Diabetologia 10, 559-565 (1974)

(C) by Springer-Verlag 1974

\title{
Effect of Diet Limitation on the Development of Diabetes in Prediabetic Chinese Hamsters
}

\author{
G. C. Gerritsen, M. C. Blanks, R. L. Miller, and W.E. Dulin \\ Diabetes and Atherosclerosis Research, The Upjohn Company, Kalamazoo, MI, USA
}

\begin{abstract}
Summary. Prediabetic Chinese hamsters born of two ketonuric diabetic parents were hyperphagic from birth. Carcass lipids and total solids were increased but plasma and pancreatic insulin were not, suggesting that hyperphagia was not due to hyperinsulinism. Hyperphagia was controlled by diet limitation of prediabetic pups. Diet limitation for the weaning period only did not alter development of diabetes, but diet limitation for the first 150 days significantly reduced onset and severity. These 150 day diet-limited prediabetics were switched to nonrestricted feeding and subsequently developed mild diabetes. Prediabetic siblings, fed ad libitum, developed
\end{abstract}

glucosuria and ketonuria, and died prematurely compared with diet-limited siblings. Prediabetics limited to a normal food intake for 30 months have remained essentially clinically normal. The data strongly suggest that appetite control mechanisms are abnormal prior to clinical signs of diabetes in the prediabetic Chinese hamster and that control of hyperphagia will retard and ameliorate the course of diabetes.

Key words: Chinese hamster, prediabetes, diabetes, diet-limitation, diabetes prevention, diabetes amelioration, and increased longevity.
Studies on diabetic hamsters have shown that they have increased food consumption and growth rates prior to onset of glucosuria $[1,2]$. These initial observations raised questions about the possible relationship of hyperphagia to the pathogenesis of diabetes in the Chinese hamster. Initial studies on diet limitation to control hyperphagia suggested that it may play an important role in the development of diabetes in this animal [3]. This conclusion is supported by similar observations in humans since restriction of food intake in man has been associated with a decreased incidence of diabetes. A decrease in the prevalence of diabetes was observed during the prolonged siege of Paris in the Franco-Prussian War of 1870 [4] and again in Europe during and immediately following World War II [5]. This paper is an update on the previous report [3] and an extension of those initial findings on diet limitation of the prediabetic Chinese hamster.

\section{Methods}

It was found that all Chinese hamster pups born to a severely ketonuric diabetic dam and sire developed diabetes [6]. This initial observation has been confirmed and extended to 160 offspring born to severely ketonuric diabetic Chinese hamsters, all of whom have become diabetic [7]. The Chinese hamsters studied in these experiments were all born from the mating of two ketonuric diabetic parents. Since all animals from this genetic background develop diabetes, they were defined as prediabetic at birth. All nondiabetic control hamsters were from inbred sublines that had been free of diabetes for a minimum of five generations of continuous brother-sister mating. Nondiabetics are tested biweekly for glucosuria by Testape ${ }^{\circledR}$ and continuously test-negative.
In the initial studies, prediabetics and nonprediabetics of similar birth weight and litter size were compared for growth rate, blood sugar [8], plasma insulin [9] and pancreatic insulin [10]. Animals were fasted overnight and killed at 15 and 25 days of age; lipids [11], proteins $[12,13]$, and solids of the eviscerated carcasses were determined. In all cases, weights of all dams were similar $(+2 \mathrm{~g})$ as were weights of all sires $( \pm 2 \mathrm{~g}$ ); this consideration was important since large parents tend to have larger pups than small parents.

The effect of hyperphagia on the change from the prediabetic to the diabetic state was studied by limiting the diet of prediabetics from: a) birth to 150 days, b) birth to weaning and c) weaning to 30 months of age. Food intake was limited during the preweaning period by fostering one half of each prediabetic litter into nondiabetic litters to make large heterogeneous litters consisting of 2 prediabetic plus 5 nondiabetic pups. The prediabetic litters averaged 4 pups while the nondiabetic litters were adjusted to 5. Thus, 2 prediabetics were fostered into the nondiabetic litters and forced to compete with the 5 nondiabetic pups, while their 2 prediabetic siblings were left with their natural mother and did not have to compete for available nutrition. After weaning, diet limitation to within normal range was accomplished by feeding prediabetic animals $2.5 \mathrm{~g} / \mathrm{day}$ of Purina Mouse Breeder Chow ${ }^{\circledR}$ [1]. Nonlimited prediabetic siblings were allowed food ad libitum. Hamsters were individually housed under standard Upjohn Chinese hamster colony conditions [14] and tested biweekly for glucosuria with Testape ${ }^{\circledR}$. After maximal Testape ${ }^{\circledR}$ values $(4+)$ were observed, they were also tested for ketonuria by Ketostix ${ }^{\circledR}$.

In the initial studies, prediabetic hamsters were switched from $2.5 \mathrm{~g} /$ day to non-restricted feeding at 150 days of age. This was done to prove that these 
animals were actually prediabetic, since it had been shown that Chinese hamsters in the Upjohn colony either develop diabetes by 5 months of age or remain glucosuria-free for life $[15,7]$. In two subsequent studies, effect of preweaning diet limitation by the fostering technique alone and the effect on the development of diabetes of postweaning diet limitation $(2.5 \mathrm{~g} / \mathrm{day})$ for 30 months have been evaluated.

\section{Results}

Birth weights of prediabetics and nonprediabetic control hamsters were similar (Table 1). At 15 and 25 days, prediabetics were significantly heavier than controls when both types were raised in equal sized to obtain more nutrition than the 5 nonprediabetic offspring of their foster mothers was emphasized in the data from two experiments which had to be terminated at 24 days (Fig. 2). In these experiments, the 15 day body weights of the fostered and nonfostered prediabetics are similar to those in Fig. 1, but the nonprediabetic pups of the foster non-diabetic mother had gained almost no weight. At 17 days of age they appeared emaciated and lethargic. They were found dead on the 18th day. Postmortem examination suggested death due to starvation since there was no body fat and the gastrointestinal tract resembled a thin thread. In these two studies, it appears that the prediabetics virtually excluded the nondiabetics from nursing activity. After elimination of the competition at 15 days, the slopes of the growth

Table 1. Comparison of fasted prediabetic with nonprediabetic Chinese hamster pups of similar litter size and parent weight (Mean Values \pm S.E.M.)

\begin{tabular}{|c|c|c|c|c|c|c|}
\hline \multirow{2}{*}{ Measurement } & \multicolumn{2}{|l|}{ Newborn } & \multicolumn{2}{|l|}{15 Days old } & \multicolumn{2}{|l|}{25 Days old } \\
\hline & Nonprediab. & Prediab. & Nonprediab. & Prediab. & Nonprediab. & Prediab. \\
\hline Number & 15 & 18 & 9 & 9 & 6 & 9 \\
\hline $\begin{array}{l}\text { Body weight } \\
\text { (g) }\end{array}$ & $1.6 \pm 0.2$ & $1.75 \pm 0.2$ & $5.9 \pm 0.2$ & $7.9 \pm 0.4^{\mathrm{a}}$ & $9.8 \pm 0.4$ & $12.2 \pm 0.03^{\mathrm{a}}$ \\
\hline $\begin{array}{l}\text { Blood sugar } \\
\text { (mg/100 ml) }\end{array}$ & - & - & $85 \pm 4.6$ & $88 \pm 5.0$ & $89 \pm 4.3$ & $94 \pm 4.5$ \\
\hline $\begin{array}{l}\text { Plas. insulin } \\
(\mu \mathrm{u} / \mathrm{ml})\end{array}$ & - & - & $3.2 \pm 1.0$ & $5.1 \pm 1.6$ & $9.3 \pm 5.0$ & $8.7 \pm 4.6$ \\
\hline $\begin{array}{l}\text { Pan. insulin } \\
\text { (U/g.) }\end{array}$ & - & - & $0.86 \pm 0.07$ & $0.69 \pm 0.08$ & $0.55 \pm 0.1$ & $0.49 \pm 0.001$ \\
\hline $\begin{array}{l}\text { Carcass lipids } \\
(\%)\end{array}$ & - & - & $1.1 \pm 0.06$ & $2.3 \pm 0.2^{\mathrm{a}}$ & $2.9 \pm 0.8$ & $4.3 \pm 0.1^{\mathrm{a}}$ \\
\hline $\begin{array}{l}\text { Carcass solids } \\
\quad(\%)\end{array}$ & - & - & $21.6 \pm 0.2$ & $25,2 \pm 0.8^{\mathrm{a}}$ & $27.3 \pm 1.7$ & $33.0 \pm 0.4^{\mathrm{a}}$ \\
\hline $\begin{array}{l}\text { Carcass proteins } \\
(\%)\end{array}$ & - & - & $14.9 \pm 1.8$ & $16.5 \pm 1.5$ & $19.0 \pm 1.0$ & $19.2 \pm 1.0$ \\
\hline
\end{tabular}

litters. Fasting blood sugar, plasma insulin and pancreatic insulin levels of prediabetics did not differ from nonprediabetics at either 15 or 25 days of age.

Total lipids and solids were significantly increased in the eviscerated carcasses of prediabetics at 15 and 24 days.

Fostering prediabetics into large litters was an effective procedure for limitation of dietary intake since body weight of the fostered prediabetics was significantly less than their nonfostered siblings at 15 days (Fig. 1). The significant difference in body weights of the fostered and nonfostered prediabetics was maintained during the last 9 days of suckling but growth rates during this period appear to be similar since the slopes of the curves are similar. Even though the 2 fostered prediabetics had significantly lower body weights at 15 days than their own natural nonfostered siblings, they still gained significantly more weight than the 5 nonprediabetic offspring of their foster mothers. This ability of the prediabetic

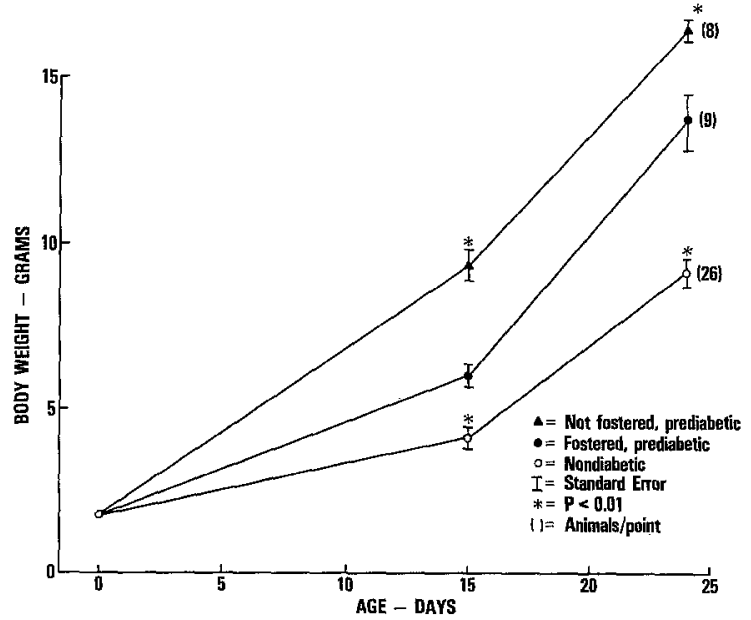

Fig. 1. Preweaning Chinese hamster body weights of nonfostered prediabetics of litter size 2 and fostered prediabetics with nonprediabetics of total litter size 7 
curves for the surviving prediabetics are quite different from those shown in Fig. 1. In this case, the fostered prediabetics grew faster than their nonfostered sibs during the last 9 days of suckling so that, at weaning on day 24, there was no significant difference in body weight.

The significant difference in weaning body weights of nonfostered and fostered prediabetics in which all nondiabetics survived was maintained by limiting

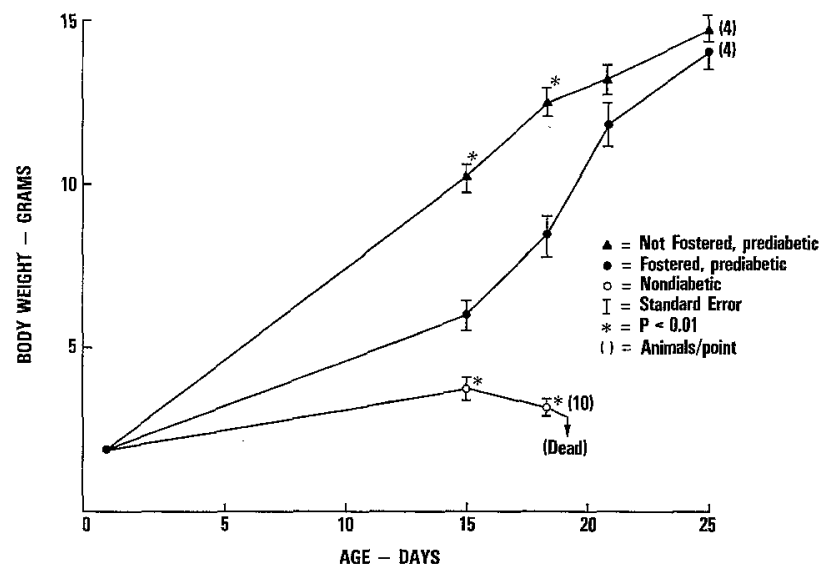

Fig. 2. Preweaning Chinese hamster body weights of nonfostered prediabetics of litter size 2 and fostered prediabetics with nonprediabetics of total litter size 7

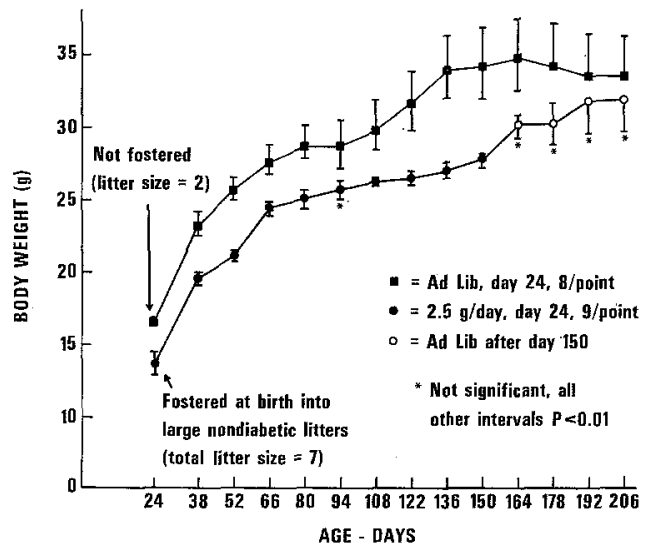

Fig. 3. Effect of food restriction on body weights of prediabetic Chinese hamsters

diet of fostered pups to an intake of $2.5 \mathrm{~g} /$ day (Fig. 3). The fostered prediabetics were maintained at a significantly lower body weight than their nonfostered and ad libitum fed siblings for the entire 150 days of diet limitation. The only exception was at 94 days which is the time of sexual maturity in the Chinese hamster. The diet-limited animals had a rapid growth spurt after the switch to non-restricted feeding, so that after 14 days they were no longer significantly lighter than their ad libitum fed siblings. The growth rate of the prediabetics limited to $2.5 \mathrm{~g} /$ day was normalized as shown in Fig. 4. Growth curves of nondiabetic weanlings fed ad libitum were similar to those of the prediabetics limited to $2.5 \mathrm{~g} /$ day and of similar initial weights. The mean daily food consumption for the nondiabeties was $2.45 \mathrm{~g} /$ day.

Diabetes developed very rapidly in the prediabetic Chinese hamster pups which were not limited to a normal food intake (Fig. 5). At 40 days of age, 7 of 8 prediabetics on non-restricted food intake had developed glucosuria $\left(4+\right.$ Testape ${ }^{\circledR}$ value $)$. In contrast, only 3 of the 9 prediabetics which were limited to a normal quantity of food developed mild glucosuria $\left(2+\right.$ Testape $\left.{ }^{\circledR}\right)$ by 50 days of age and remained at

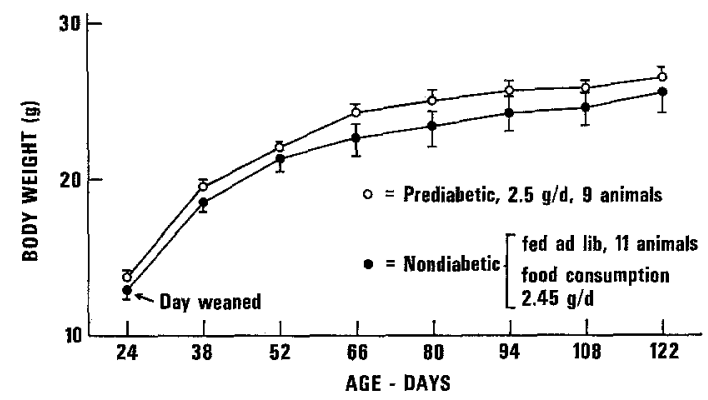

Fig. 4. Comparison of growth rates of nondiabetic Chinese hamsters fed ad libitum and prediabetics limited to $2.5 \mathrm{~g}$ of food per day

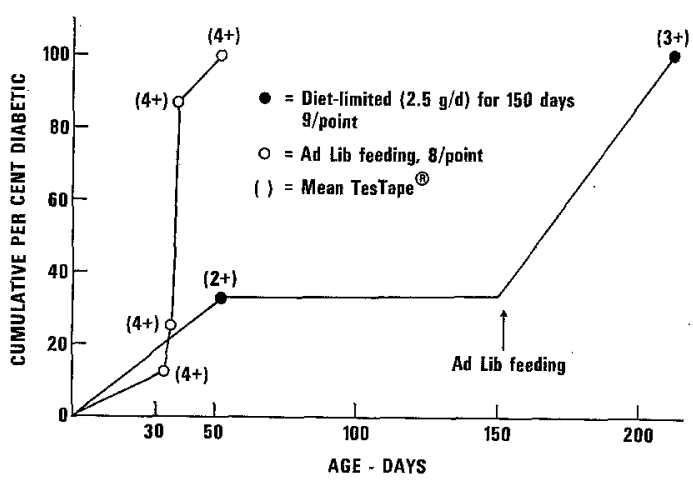

Fig. 5. Difference in age of onset and severity of diabetes in diet-limited and ad libitum fed prediabetic Chinese hamsters

$2+$, but when switched to non-restricted feeding, glucosuria increased to $4+$ within a few days. The other 6 prediabetics which were fostered and subsequently limited to $2.5 \mathrm{~g} /$ day did not develop glucosuria as long as they were limited to this quantity of food intake. However, within 50 days after placing these animals on non-restricted diet they all showed mild glucosuria $(2+$ to $3+)$. Further, these animals remained very midly diabetic for their entire life span.

Seven out of the eight hamsters fed ad libitum also developed ketonuria, but ketonuria never developed 
in their siblings which were diet-limited for the first 150 days (Fig. 6 ).

It was also observed that 5 of 8 of the hamsters fed ad libitum died prior to 300 days of age (Fig. 7). The 3 that survived beyond 300 days died prior to 18 months of age. In contrast, all the siblings which were diet-limited for the first 150 days survived beyond two years.

The significant effect on body weight of prediabetics due to fostering into large litters was overcome during the first 14 days of non-restricted feeding after weaning (Fig. 8). Preweaning diet-limitation alone had no significant effect on onset or severity of

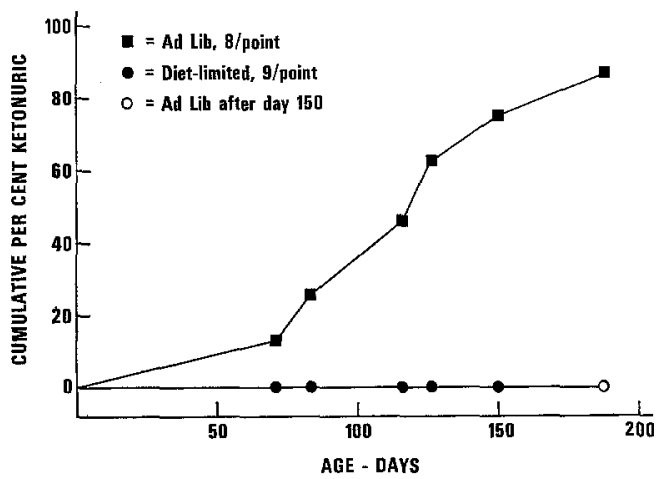

Fig. 6. Incidence of ketonurics in ad libitum fed versus diet-limited Chinese hamsters

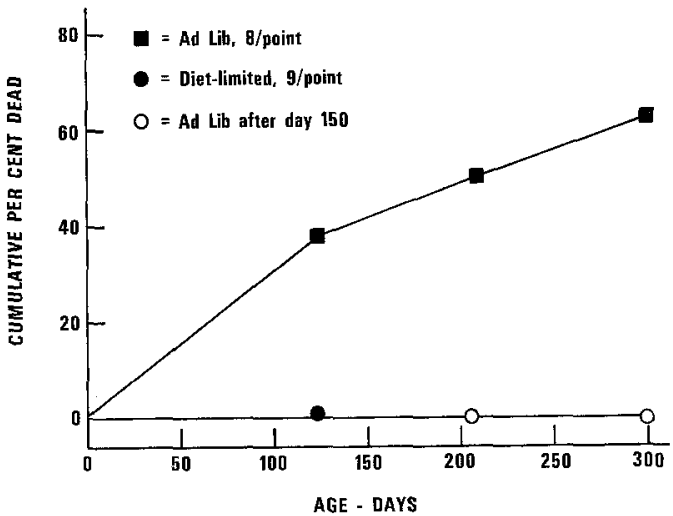

Fig. 7. Mortality in ad libitum fed versus diet-limited Chinese hamsters

diabetes, development of ketonuria or survival in these prediabetic Chinese hamsters. The results were similar to data shown for ad libitum fed animals in Figs. 5, 6, and 7 .

Limitation of diet to $2.5 \mathrm{~g} /$ day after weaning resulted in a reduced growth rate, but these dietlimited prediabetics slowly caught up to their ad libitum fed siblings (Fig. 9). At 200 days of age, body weights were no longer significantly different. However, development of glucosuria was markedly different in these prediabetic hamsters (Fig. 10). The ad libitum

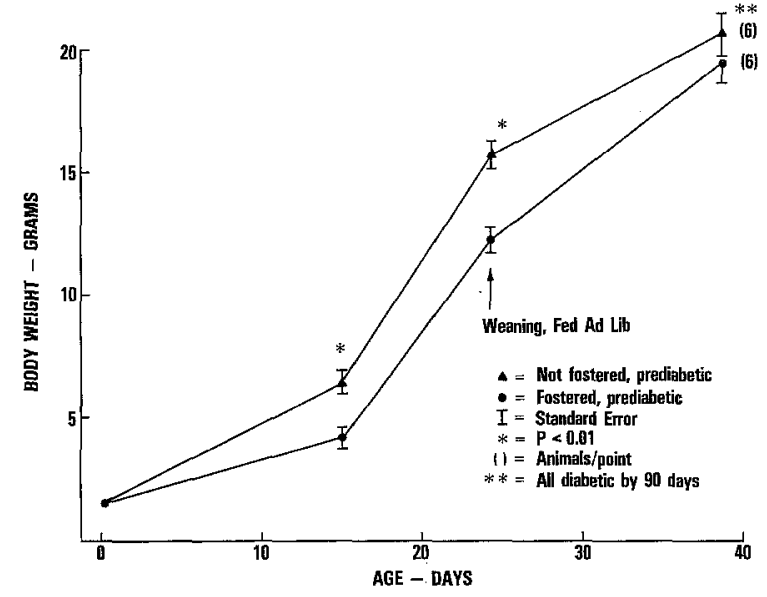

Fig. 8. Body weights of fostered prediabetics fed ad libitum after weaning

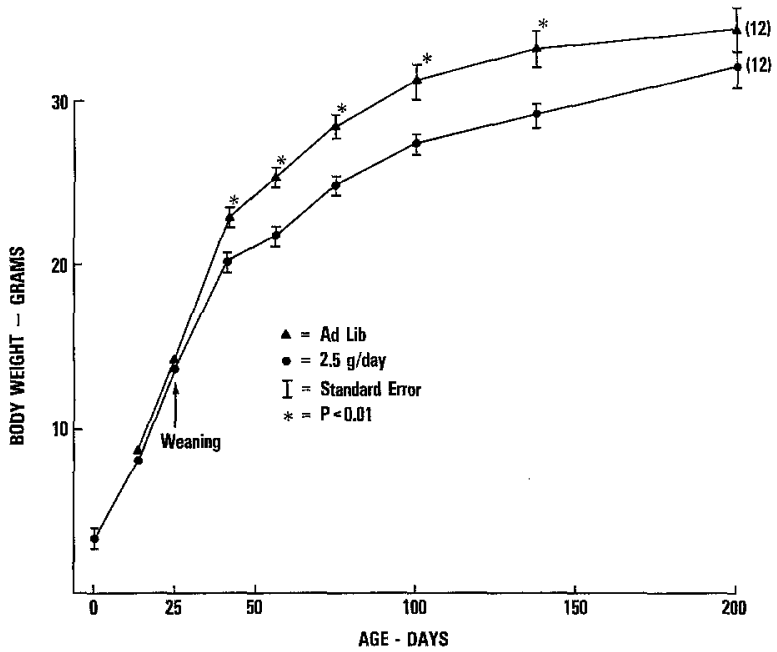

Fig. 9. Effect of diet restriction after weaning on body weight of prediabetics

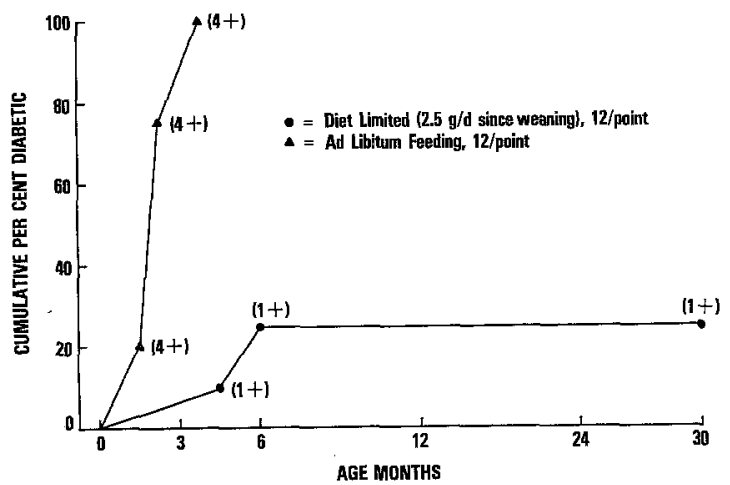

Fig. 10. Incidence and age of onset of diabetes in $\mathrm{ad}$ libitum fed versus postweaning diet-limited prediabetics 
fed siblings developed diabetes very rapidly; in some, diabetes progressed to ketonuria and premature death. Again, only 3 of the 12 animals which were kept on $2.5 \mathrm{~g} /$ day for 30 months showed a trace of glucosuria which was intermittent. They have never progressed to consistent mild glucosuria and the other nine have never shown any glucosuria.

\section{Discussion}

The significant increase in body weight and carcass fat content supports the contention that prediabetic Chinese hamsters are hyperphagic from birth. These results support and extend the previously observed hyperphagia of prediabetics following weaning [1]. Since plasma insulin levels were not elevated in the prediabetics, it can be concluded that hyperphagia was not due to hyperinsulinism, which would be expected to increase food intake [16], and that the increased body fat did not influence plasma insulin levels of the prediabetic.

The observation that prediabetic Chinese hamsters have preweaning hyperphagia suggests that appetite control was abnormal at birth in these animals. It is not clear if this resulted from genetic or environmental. influence. Since all the prediabetics had ketotic dams, the intrauterine environment may be an important factor influencing the preweaning food intake. It is generally agreed that, in man and animals, glucose crosses the placental barrier, and that although fetal blood sugar levels are lower than maternal levels, there appears to be a significant correlation $[17,18]$. There is also evidence to suggest that elevated fetal blood sugar levels can produce relative fetal hyperinsulinism $[19,20]$. Furthermore, it is possible that the high levels of maternal blood ketone-bodies may also pass the placental barrier. Thus abnormal blood levels of glucose, insulin and ketone-bodies, alone or in combination, may influence the developing appetite control mechanisms of the prediabetic Chinese hamster in utero. Another possibility is that genes, alone or in combination with factors emanating from the maternal environment, may influence these developing appetite control mechanisms. It should be pointed out that only offspring from two ketonuric Chinese hamsters are predictably prediabetic $(100 \%$ incidence of diabetes) and that offspring of two nonketotic diabetic parents do not all develop diabetes [6, 7]. Further, it has been postulated that ketonuric, diabetic hamsters have a different genotype than nonketonuric, diabetic hamsters [21]. The possibility that genetic background and maternal ketonemia may influence appetite control mechanisms in the prediabetic Chinese hamster neonate is supported by recent observations that "hybrid prediabeties" from nonketonuric diabetic parents of two different inbred sublines did not display accelerated growth or hyperphagia during their prediabetic phase [21]. It is obvious that similar data from prediabetics with similar genotypes to those studied here prenatally nutured in "nondiabetic" surroundings are needed to determine the influence of intrauterine environment on food intake and subsequent development of diabetes. Two approaches toward an answer to the above question are transplantation of the ovary from a ketonuric diabetic to a genetic nondiabetic, or transplantation of pancreas or islet to normalize the ketonuric diabetic mother.

It is apparent that the fostering procedure was effective in limiting food intake prior to weaning since the prediabetic pups did not grow as rapidly as their nonfostered siblings. The appetite drive, however, of the fostered prediabetics was greater than their foster mother's own pups since they gained significantly more weight. In two cases, the two fostered prediabetics apparently had such extreme hyperphagia that the 5 nondiabetics were unable to obtain sufficient nutrition to maintain life (Fig. 2). It is interesting to note that after the foster mother's 5 pups died of starvation, the 2 remaining fostered prediabetics gained weight faster than their siblings left with their natural ketotic dam. This observation suggests that quantitative or qualitative differences in milk from ketonuric or nondiabetic dams were not responsible for the different growth rates. In fostered litters where the nondiabetic pups survived (Fig. 1), growth rates were similar for both fostered and nonfostered pups from 15 to 24 days since the slopes of the growth curves are similar. This may be explained by the observation that mothers with large litters have been known to soften food by chewing it and then forcing it into their pups from 13 days until they are weaned.

It should be pointed out that fostering prediabetics into large litters and subsequent limitation of food to $2.5 \mathrm{~g} /$ day did not significantly alter body weight at weaning time, as compared with nondiabetics from litters and parents of similar size, or alter their subsequent growth rate but simply normalized it. This is shown in Fig. 4 where weaning weights of nondiabetic pups and subsequent growth curves are similar to the food-limited prediabetics.

Lack of significant difference in body weight between prediabetios fed ad limitum and their dietlimited siblings at 94 days of age may be due to the advent of sexual maturity when the growth rate tends to taper off. Variation of body weights of the ad libitum fed predjabetics was considerably greater than that of the diet-limited group. This may be due to variable food consumption in the ad libitum fed group compared to the consistent intake of $2.5 \mathrm{~g} /$ day for the diet-limited animals. This is supported by recent observations that food consumption is quite variable in the Chinese hamster [22]. In addition, the ad libitum fed animals developed diabetes of varying severity early, (Figs. 5 and 6 ) and this might also contribute to the variation in body weights. When 
prediabetics were switched from limited to nonrestricted feeding their food consumption increased to $3.0-3.5 \mathrm{~g} /$ day. It is interesting to note that their food consumption remained at this level for the rest of their lives (over 2 years) and never increased to the expected level of 4 to $5 \mathrm{~g} /$ day normally consumed by the diabeties [22]. This observation suggests that the diet limitation for the first 150 days of life has a prolonged effect on food intake.

The data show that limiting food intake of the hyperphagic prediabetic hamster to the lower limit of normal $(2.5 \mathrm{~g} /$ day) results in a milder diabetic and retards the onset of glucosuria. Further, diet limitation for only 150 days eliminated development of ketonuria which under normal circumstances would have been expected in some of these prediabetics [6, 7]. In addition, all the ad libitum fed prediabetics died prior to 18 months, while all their 150 day diet-limited siblings survived for just over two years. These observations are consistent with epidemiological findings from the Upjohn colony $[21,15]$. Limitation of diet only during the preweaning period did not alter the development of diabetes, suggesting that diet limitation must persist beyond the weaning age of 24 days. Diet limitation to $2.5 \mathrm{~g} /$ day from weaning for 30 months resulted in a slower growth rate in the prediabetics as compared to their ad libitum fed siblings, but they eventually attained similar body weights. Prolonged diet limitation, however, essentially prevented development of diabetes in these prediabetics and their life expectancy was normalized [21]. Since dietary restriction for long periods of time is difficult, it will be of interest to determine if diet limitation from weaning to 100 days of age or the advent of sexual maturity will be sufficient to retard onset and reduce the severity of diabetes in prediabetic Chinese hamsters.

It may be concluded from these studies that normalizing food intake of the hyperphagic prediabetic Chinese hamster has a marked influence on onset and severity of the disease. The increase in longevity suggests the benefits of delaying the development and/or reducing the severity of the disease. It appears that continued diet limitation will essentially keep the prediabetic free of clinical symptoms of diabetes and normalize life span.

If prediabetics from ketonuric parents are allowed food ad libitum, they develop ghucosuria very early which is generally followed by ketosis and premature death in many of them. These observations lend considerable confidence to the concept that environmental modification can alter the course of a genetically influenced syndrome such as diabetes.

Whether the early increase in body weight and lipid content prior to hyperglycemia contributes to early development of diabetes is not known. This, however, is possible, since obesity has been implicated in the development of spontaneous diabetes in other laboratory animals $[23,24]$ and also of maturity-onset diabetes in man $[25,26]$. In addition, there appears to be positive correlation between obesity, carbohydrate intolerance and hyperinsulinism in childhood [28]. This concept is supported by the observation that after switching the animals which had been on limited diet to non-restricted feeding, they gained weight prior to onset of glucosuria. Their food consumption, however, did not become so excessive that they would progress to severe diabetes, as evidenced by a lack of ketonuria and premature death.

Unfortunately, there has been no report in the literature as to the effects of diet limitation on human prediabetics. There is, however, a suggestion that emotional problems and stress during the prediabetic years may lead to poor nutritional habits which may have an effect on development of diabetes [28]. Other circumstantial evidence suggests that severe caloric restriction during wars can decrease the prevalence of diabetes $[4,5]$.

It is apparent that appetite control is abnormal in prediabetic Chinese hamsters with two ketonuric parents. As long as this abnormality can be controlled, it appears that onset of diabetes and severity can be prevented or minimized, providing more evidence that diabetes, as it is presently understood, is due to an interaction of environmental and genetic factors. Whether this abnormality is of genetic or environmental origin or a combination of the two is unknown; this question must be answered by further investigations. The data suggest that, if environmental factors can be understood and manipulated properly, the clinical symptoms and, perhaps, the consequences of abnormal metabolism may be prevented in the prediabetic.

Acknowledgment. The authors gratefully acknowledge the helpful critism and suggestions of Mrs. F.L. Schmidt during the course of these investigations and preparation of the manuscript. The authors wish to pay special tribute to Mr. L.B. Needham, deceased, without whose skill and dedication the prediabetic Chinese hamster may never have been produced. It is with great sadness and a deep sense of loss that we dedicate this manuscript to his memory.

\section{References}

1. Gerritsen, G.C., Blanks, M.C.: Preliminary studies on food and water consumption of prediabetic Chinese hamsters. Diabetologia 6, 177-179 (1970)

2. Gerritsen, G.C., Chang, A.Y., Schneider, D.I., Needham, L.B., Blanks, M.C.: Studies on prediabetic Chinese hamsters. Diabetes 20, 356 (1971)

3. Gerritsen, G.C., Dulin, W.E.: Effect of diet restriction on onset of development of diabetes in prediabetic Chinese hamsters. Acta diabet. lat. 9 (Suppl. 1), $597-$ $613(1972)$

4. Bouchardat, H.: De La Glucosurie du Diabète Sucré. Paris 1883

5. Pyke, D.A.: In: Clinical diabetes and its biochemical basis (Oakley, W.G., Pyke, D.A., Taylor, K.W., eds.) p. 245. London: Blackwell 1968 
6. Gerritsen, G.C., Needham, L.B., Schmidt, F.L., Dulin, W.E.: Studies on the prediction and development of diabetes in offspring of diabetic Chinese hamsters. Diabetologia 6, 158-162 (1970)

7. Dulin, W.E., Gerritsen, G.C.: Interaction of genetics and environment on diabetes in the Chinese hamster as compared with human and other diabetic animal species. Acta diabet. lat. 9 (Suppl. 1), 48-84 (1972)

8. Gerritsen, G.C., Dulin, W.E.: Characterization of diabetes in the Chinese hamster. Diabetologia 3, $74-84$ (1967)

9. Blanks, M.C., Gerritsen, G.C.: An ultramicro assay for insulin. Proc. Soc. exp. Biol. (N.Y.) 146, 448-452 (1974)

10. Zaharko, D.S., Beck, L.V.: Studies of a simplified insulin immunoassay using cellulose powder. Diabetes 17, 444-457 (1968)

11. Folch, J., Lees, M., Sloan Stanley, G.H.: A simple method for the isolation and purification of total lipids from animal tissues. J. biol. Chem. 226, 497509 (1957)

12. Natelson, S.: Microtechniques of clinical chemistry. p. 101. Springfield, Ill.: C.C. Thomas 1961

13. Snell, C.T., Snell, F.D.: Colorimetric methods of analysis. p. 184. Toronto: D. van Nostrand 1945

14. Gerritsen, G.C., Dulin, W.E.: Serum proteins of Chinese hamsters and response of diabetics to tolbutamide and insulin. Diabetes 15, 331-335 (1966)

15. Schmidt, F.L., Leslie, L. G., Schultz, J.R., Gerritsen, G.C.: Epidemiological studies of the Chinese hamster. Diabetologia 6, 154-157 (1970)

16. May, K.K., Beaton, J.R.: Hyperphagia in the insulin-treated rat. Proc. Soc. exp. Biol. (N.Y.) 127, 1201-1204 (1968)

17. Oakley, N.W., Beard, R.W., Turner, R.C.: Effect of sustained maternal hyperglycaemia on the fetus in normal and diabetic pregnancies. Brit. med. J. 1972 I, $466-469$

18. Kraner, F., Joyce, J., Young, M.: The influence of high maternal plasma gucose levels and maternal blood flow on the placental transfer of glucose in the guinea pig. Diabetologia 9, 453-456 (1973)

19. Farquhar, J.W.: The significance of hypoglycemia in the newborn infant of the diabetic woman. Arch. Dis. Childh. 31, 203-211 (1956)

20. Cormblath, M., Joassin, G., Weisskopf, B., Swiatek, K.R.: Hypoglycemia in the newborn. Pediat. Clin. N. Amer. 13, 905-920 (1966)

21. Gerritsen, G.C., Johnson, M.A., Schultz, J.R., Soret, M.G.: Epidemiology of Chinese hamsters and preliminary evidence for genetic heterogeneity of diabetes. Diabetologia 10, $581-588$ (1974)

22. Gerritsen, G.C., Blanks, M.C.: Characterization of Chinese hamsters by metabolic balance, glucose tolerance and insulin secretion. Diabetologia 10, $493-499(1974)$

23. Coleman, D.L., Hummel, K.P.: Studies with the mutation-diabetes in the mouse. Diabetologia 3, $238-248$ (1967)

24. Nakamura, M., Yamada, K.: Studies on a diabetic KK strain of mouse. Diabetologia 3, 212-221 (1967)

25. Allison, R.S.: Carbohydrate tolerance in overweight and obesity. Lancet $\mathbf{1 9 2 7}$ I, 537-540

26. Joslin, E.P., Dublin, L.T., Marks, H.H.: Studies in diabetes mellitus. IV. Etiology. Amer. J. med. Sci. $192,9-23(1936)$

27. Martin, M.M., Martin, A.L.A.: Obesity, hyperinsulinism and diabetes mellitus in childhood. $J$. Pediat. 82, 192-201 (1973)

28. Stein, S. P., Charles, E. : Emotional factors in juvenile diabetes mellitus: A study of early life experience of adolescent diabetics. Amer. J. Psychiat. 128, 700-704 (1971)

Dr. George C. Gerritsen

Diabetes and Atherosclerosis

Research

The Upjohn Company

Kalamazoo, Mich. 49001

USA 